\title{
Chapter 3 \\ Elites and Expertise: The Changing \\ Material Production of Knowledge \\ for Policy
}

Jennifer T. Ozga

\subsection{Introduction: Elites, Expertise, Knowledge, Policy}

The terms 'experts', 'expertise' and 'knowledge' are used frequently in current discussion by policymakers and in academic literature on policymaking in education and other fields, though often in loosely defined or contradictory ways. Experts face criticism as enemies of the free flow of information, as anti-democratic, serving vested interests and conspiring against society to protect economic and political elites against challenges to their power and interests. Experts are, nevertheless, invoked frequently by policymakers in support of specific policy directions, yet also castigated by them for their failure to provide coherent, incontrovertible and 'actionable' knowledge (Grundmann and Stehr 2012: 19). At the same time as the public is confidently told that policy can now be based securely on objective scientific fact, policymakers state that society 'has had enough of experts' (see, e.g., Michael Gove, then Secretary of State for Education in England, quoted in Clarke and Newman 2017: 1).

The revolt against 'expertise' is illustrated in current popular and media hostility to ruling elites, to 'normal' politics, and is brought into sharp focus in the UK by Brexit and its aftermath, including political, media and public hostility to EU bureaucrats and those seeking to maintain Europe's four freedoms. Bureaucracy or perhaps, more accurately, technocracy is represented in the media and in populist discourse as dominated by economic agendas and bureaucratic logic, in a context where nation states seem less able to act independently of global capital and are increasingly subject to the authority of supranational institutions (Jessop et al. 2008; Bevir 2013; Grek 2015; Hartong 2015).

I should note that I am not engaging here with debates about the nature of scientific knowledge nor with competing models of the policy-knowledge relationship.

\footnotetext{
J. T. Ozga $(\bowtie)$

Department of Education, University of Oxford, Oxford, UK

e-mail: jennifer.ozga@education.ox.ac.uk 
Previous research with colleagues in the project 'knowandpol' ${ }^{1}$ suggests that policymakers and scientists follow opposing logics: as Demsky and Nassehi put it, science is based on 'debating, doubting and rejecting knowledge claims' (2014: 113), while policy:

... obeys a diametrically opposed logic. Policy is a practice of making visible and identifiable decisions that are supposed to change the social world. In such a context, the admission of doubt is fatal. (2014: 113)

That project also identified knowledge, including scientific knowledge, to be best understood as socially constructed, and as shaped at least in part by the contexts of its production, and by the social relations in which it is embedded.

In what follows, I want to look more closely at the contexts of production of expertise, and at the objects and artefacts through which knowledge is expressed, with a focus on different forms of knowledge production, comparing and contrasting those forms available to policymakers in the 1970s and 1980s, with those mobilised in the current conditions. In looking at education as a policy field in which knowledge production may be interrogated over time, I suggest that we can identify significant change in the nature and intensity of the knowledge-policy relationship, resulting, at least in part, from the recent explosion of knowledge production, its encoding in data, combined with its increased capacity to travel at speed. As an OECD publication puts it: 'the key question posed is: how do governance and knowledge mutually constitute and impact on each other in complex education systems?' (Fazekas and Burns 2012: 6).

The research that I draw on exploring 'mutually constitutive' contemporary governing forms has been carried out in funded research projects with a number of colleagues $^{2}$ in Europe over a period of years, starting in 2006. Many of our main conclusions can be found in previous publications [see, e.g. Ozga (2016), Lawn and Grek (2012), Grek and Lindgren (2015), Ozga et al. (2012), Ozga and Lawn (2014), Ozga et al. (2011), Grek and Ozga (2010)]. For the purposes of this discussion, the key points that characterise this research may be helpful in situating the argument in this text and may be summarised as follows:

1. Changes in governing and changes in knowledge are interdependent.

2. In the neo-liberal imaginary, society is increasingly organised in networks constructed and held together through the flow of comparative knowledge and data.

3. As governing becomes more networked, more flexible and interrelated, so too does knowledge change, moving from disciplinary silos into a more problembased form, involving new actors in its production.

4. Valued knowledge for policy identifies what needs to be done, or 'what works'.

\footnotetext{
${ }^{1}$ Knowledge and Policy in Health and Education (www.knowandpol.eu).

${ }^{2}$ There are too many people involved in this research to list here, but I owe a particular debt to Luis Miguel Carvahlo, John Clarke, Sotiria Grek, Martin Lawn, Joakim Lindgren, Linda Ronnberg and Eric Mangez.
} 
5. Experts and consultants, as well as key actors in education (e.g. inspectors) are responsible for translating coded knowledge and are also 'coded' by data.

6. Their work is thus increasingly 'political work', but its politics is concealed in the processes of knowledge production and exchange.

To elaborate, nation state-centred governing is in decline, hierarchical organisation and formal regulation are increasingly displaced by networks and standards, and formal policy actors are replaced by a diversity of actors, public/private hybrids and non-formal actors (consumers, third-sector members, media) and guided in action by data. In the context of increasing involvement of new actors-especially corporate actors like Pearson and McKinsey_-in data production and use, data systems enable relations to be established between political and other authorities, offer ways of forming and maintaining these connections and supply devices and techniques that make tactical aims practical (Rose and Miller 1992). Data systems create governing assemblages that shape individual conduct while apparently enabling autonomous, choice-making activity. These data are public — they are described as 'transparent'; they are no longer produced for and distributed among the bureaucratic elite but distributed among and doing political work in the wider population, not only for politicians and civil servants. Local government and schools that used to be relatively closed to public and central government scrutiny are now rendered visible and calculable (Ozga et al. 2011: 92). Data expressed as public rankings, league tables and PISA results are both 'official and popular' knowledge forms, and so, as Piattoeva (2014) argues, we can see them as doing political work; for example enabling and consolidating control over a wide network of actors and institutionslocal authorities, schools and teachers included.

The 'popular' work they do is make connections to individual citizens/learners/ pupils in such a way as to steer or mediate their decisions and actions in the economy, family sphere and any other aspect of everyday life (cf. Rose and Miller 1992: 180). Data thus 'make people up'-make them visible and encourage people to think of themselves in particular ways - to classify themselves. In schooling, data act powerfully on individuals and groups through their predictive capacities, and individuals accept and work with this information, becoming engaged in their own production. Digital data construct schools as 'computational' projects. Here, the 'modelling' of education through digital data fosters a sense of algorithmically driven 'systems thinking' through which complex (and unsolvable) social problems associated with education can be seen as complex (but solvable) statistical problems.

This new governing-knowledge relationship creates a demand for new skills and new kinds of work from particular groups of actors who are positioned at key points of intersection of knowledge production and practical problem-solving. Such work demands skills in translating information into 'practical knowledge', mediating conflict and brokering interests (Clarke et al. 2015). There is a growing literature on the influence, interconnections and work of networks of experts (Ball and Junemann 2012; Shiroma 2014), who promote cognitive consensus among policymakers based on the linked processes of simplification of large volumes of information and the dominance of international comparison as a basis for policy (Ozga 2015). The rapid 
growth of experts, advisers and consultants in education arises from the rapid expansion of data-based knowledge; simplification strengthens the trend towards comparison and the search for 'actionable knowledge' derived from patterns in comparative data, and also increases the influence of analysts and gives considerable power to those who can interpret data and identify those 'levers for action' (Grundmann and Stehr 2012: 20-21) that make political action easier.

These experts are 'more than the diffusers of ideas; they develop conceptual knowledge in order to promote educational reforms, drawing on their substantial experience as policy advisers to governments and IOs'. Moreover, 'their attributes as experts and consultants tend to obscure the ideological and political dimension of their activities of knowledge production for policy' (Shiroma 2014: 2).

Despite the claims of big data proponents (see, e.g. Anderson 2008), data do not speak for themselves but contain coded policy choices and require interpretation. The political nature of that interpretation is often concealed, as Shiroma points out, because the label 'expert' confers scientific status and authority. Concealment of the political work that expertise does is also enabled because much of the activity around data involves the application of rules, standards and processes stored in algorithms and technical formulae that mobilise the particular preferences of their creators and are applied without explicit reference to the choices they contain (Higgins and Larner 2012: 7). As Williamson (2016: 4) puts it: 'Digital software technologies, data systems and the code and algorithms that enact them have become powerful yet largely hidden influences in the governing of education'.

A focus on the political work that data do draws attention to the processes of brokering and translation that are key in data work for policy and to the kinds of experts who are doing this work in particular institutions with their own work cultures, technical capacities and interests. The growth of this form of expertise is recognised as a transnational phenomenon, with experts increasingly working between national and transnational arenas, and claiming status as a "new governing elite' (Stone 2013: 41 Lawn and Grek 2012: 75) also described as a 'magistracy of influence' (Lawn and Lingard 2002: 292) and a new 'European technocracy' (Normand 2016: 129).

These groups operate globally to promote convergence in education policymaking through the construction of models of education systems that are claimed to be simultaneously effective, efficient and equitable. A global convergence of educational and cultural worlds is understood as an inevitable facet of modernity driven by the logic of technology, science and the idea of progress that is, ultimately, dependent on scientific advance. The authority of science is invoked to sustain this approach, but, as Dale points out, the idea of science that is invoked here fails to acknowledge that 'scientific authority' does not in itself ensure acceptance of models, without reference to 'the set of political conditions' under which they are advanced (Dale 2000: 445). Nor is it attentive to the related recognition that scientific knowledge is produced, accepted and contested in specific contexts (Connell 2007; Demszky and Nassehi 2014).

In the next section, I want to highlight the contrast between the research findings summarised above, drawn from work on the impact of performance data on the 
governing of education, and which reveals the speed and power of data to shape relations and practices, and the almost data-free landscape that characterised the research environment of policymaking from the 1940s to the 1970s and 1980s. Here I am drawing on a database of interviews that I have carried out with policymakers from the 1970s onwards, some of which were retrospective, and some of which have been the basis of earlier publications (see, e.g. Gewirtz and Ozga 1990, 1994). Returning to that period demands attention to changes in what Dale identifies as the 'political conditions' of knowledge production and also draws attention to change in the material conditions of knowledge production, highlighting how changes in knowledge technologies - which may be summarised as a shift from paper-based knowledge to digital data-impact on the nature and composition of education policy elites. By material conditions of production is meant attention to (1) the social, political and economic relations that structure work (including knowledge production) and (2) the instruments and material artefacts seen as 'key bearers' of knowledge (Freeman and Sturdy 2014).

\subsection{The Pre-digital Production of Knowledge for Policy}

A return to the policy world of the 1940s-1980s, through exploring and re-analysing interview and textual data, is also a revisiting of my own past as a researcher and administrator. I was an administrator in the headquarters of the National Union of Teachers in the 1970s, and a researcher at the Open University in the 1980s, and in both of these work contexts, I was able to record interviews with policymakers, in the case of the OU as part of the study of education policy, and for the NUT as part of my work in gathering and analysing knowledge to help support Union officers. In this period work in educational organisations had much in common in respect of organisational practices and cultures, which were often modelled on civil service norms and practices. The NUT-a major player in policy in the 70s, but about to enter a turbulent period and a decline in influence-was deliberately constructed to parallel the structure of the Ministry (later the Department) of Education in England. It had the same organisation of responsibilities as the Ministry, and its local organisation reflected the organisation of the Local Education Authorities, then responsible for local provision of schooling and other education services. In their design and assumptions, the Union's working practices were also a reflection of the Ministry's in that NUT administrators were understood to provide the objective knowledge resources that informed the practical policymaking activity of the Union's elected officers (just as officials in Whitehall were said to act without bias but draw on experience in informing politicians).

In thinking about knowledge production at that time, it is important to remember that the 1970s are pre-digital. There is no Internet and no email and communications work through telephone and post, or person to person. Letters are still often handwritten or dictated, then typed by clerical staff (who keep and file duplicates). Copying is messy and tedious, large-scale production of material (policy documents, 
research reports) has to be printed in systems that do not allow for easy correction or revision. Photocopying developed in the 1980s and laser printing by the mid to late 1980s, and word processing then arrived and became widespread in the 1990s. These changes in information technology bring huge changes in work organisation (which are discussed, e.g. in Fox and O'Connor 2015, Zammuto et al. 2007). But the dominant instruments of knowledge accumulation and distribution in the period up to the late 1980s are paper-based and need people to construct their content. This paper-based material is heavy, and it is not the weightless, flexible, transportable material of digital data moving around the Internet-it requires physical manipulation and categorisation in order to do knowledge work. Storing and retrieving paperbased data is a skill that is both demanding and very time consuming, which requires attention to and design of hierarchies of importance, that relate to hierarchies of work organisation. So, for example, the listing of educational 'plant' (buildings and equipment) and salary costs constitutes the basic data for system management: the recording of examination data is not centralised and does not include the whole school population. Paper is the medium through which information is gathered: for example the NUT carried out frequent paper-based surveys as a way of informing the direction of policy and keeping in touch with its (then) 300,000 strong membership. These surveys had to be constructed, distributed and analysed in paper form.

These processes obviously shaped the kinds of knowledge that was produced, for example in the Union's development of responses from members or local officers about education policy. These queries arrived as letters, which had to be recorded and classified, so that they could be directed to the appropriate source of information, from which a reply could be drafted for official signature. Responses also needed to be classified and recorded. This activity gradually created a knowledge base among those engaged in it, who developed knowledge of the policy 'line' on current issues.

Importantly, that knowledge base depended heavily on precedent. Precedent also guided Committee decisions, and perhaps the power of precedent was most vividly illustrated at the Union's Annual Conference. This was, and still is, its main policymaking forum where membership and officers debate and decide policy directions. In the 1970s, administrative staff were responsible for transporting to the Conference site all potentially relevant materials relating to current debates, packed in a large wicker hamper, so that they could retrieve the correct materials that guided action.

The point here is that this form of knowledge production, which also characterised the work of the Department of Education and the Local Education Authorities, was strongly shaped by past practice. The past was the source of guidance for action in the present, the future barely featured. The production of knowledge was shaped by the very concrete knowledge forms (files, memoranda, log books) that guided the present. These were 'heavy' but not inert, as they became actionable through the interaction of the paper archive (i.e. in Freeman and Sturdy's terms, the inscribed knowledge) with the embodied knowledge of experienced administrators and officers (Freeman and Sturdy 2014).

Examination of the material production of knowledge in the Ministry/Department of Education in the period up to the 1980s in England reveals that the preferred form 
of knowledge production and dissemination was the administrative memorandum. These documents are lengthy, graceful and erudite essays, which both built and expressed consensus around key principles for the governance of education that were largely preoccupied with preserving a hierarchy of schooling to select and maintain a small meritocratic elite. Their rules of production were largely implicit and echoed the rules of production of the Oxford undergraduate essay. Scrutiny of personal correspondence between civil servants and local government officers, and of minutes of meetings and conversations, reveals a rather sharper focus on problems, often solved through informal agreements that operated to close down controversy (Gewirtz and Ozga 1990).

Capacity in the production of memoranda and other paper-based knowledge forms was understood as best developed over time, from knowledge of past practice. Learning 'on the job' - informally described as 'sitting by Nellie' though there were vanishingly few female senior civil servants-was standard practice, once selection from the correctly socialised pool of candidates had been made. Experience was valued. My interview data provide examples. Here is Sir Toby Weaver, Deputy Permanent Secretary in the Department from 1962 to 1972, describing the workings of the Department's administrators:

As part of your stock in trade as an educational administrator you will be expected to have acquired a wide range of knowledge about both the work of the Department and the problems that beset the educational world. By the time you have been in the Department for some years you will have become familiar with the chief reports of the Councils, Committees and Working Parties of different kinds whose analyses of problems and recommendations for solving them form one of the main sources of material for policy making.

(For example), as an educational administrator you will certainly be familiar with what the Plowden report said about nursery education. You will know what the law says about the topic and how in the past it has been interpreted by the Department. You will have at your elbow any regulations that bear on it. You will be familiar with the past and present policy of the Department, be ready to explain and defend it, be aware of its limitations. You will do your best through books, journals and research articles to keep abreast of the development of expert thinking on the subject, and to read the press cuttings that cross your desk every day, in the hope of spotting anything relevant......Finally you will be wise to keep in touch one way or another with the Secretary of State's day to day thinking on the subject.

From where we are now, these procedures seem painfully slow and startlingly removed from connection with the public (or with public representatives). Indeed, even in the 1970s, and especially after the oil crisis of 1979, there was pressure for change on stately education bureaucracies. These pressures came from the OECD, which characterised policymaking in education in the 1970s in England as secretive, conservative, committed to maintaining the status quo, and as disconnected from other policy developments (especially those concerned with employment/ skills/economy). A subsequent Parliamentary Select Committee enquiry, at the height of the oil crisis, demanded reform of the DES, stressing in particular the need for connections between education and the economy, and for more consultation and openness, to which the DPS (Weaver again) responded that the DES did not go in much for consultation because it 'did not wish to encourage premature speculation' (Weaver, in House of Commons 1975-1976). 


\subsection{Changing Knowledge Production}

The tone of response to external critique and the assumptions that inform it - of reliance on what is known and reluctance to imagine the future-was challenged throughout the 1970s in debates about the structures of schooling and about its capacity to meet different needs (first in relation to gender, then ethnicity) on an equal basis. That period of debate and disruption was followed by (and perhaps produced) Thatcher's 'reform' agendas which of course included significant changes in the Department and in the local government of education too. The Civil Service Efficiency Unit was established under ex-businessman Derek Rayner in the mid '80s to drive cultural change in Whitehall, prioritising technical expertise and recruiting 'action oriented thinkers-people who can get things done'. The Civil Service College was encouraged to develop contacts with top management in business and industry, and a new breed of political advisers begin to make their presence felt. This is happening as word processing becomes widespread, spreadsheets become the new currency of knowledge exchange, and new public management ideas are spread through technologies that disrupt the previously tightly bounded knowledge regimes of education in the public sector, in the Department, in the LEAs. Here we see a change in the knowledge and expertise that are valorised in governance - a shift to generic management (Cutler and Waine 1998), where universal principles are applied across public sector organisations, and generic knowledge and skills are demanded of public servants. Bureaucracies are demonised as rule bound, and precedent driven, as vulnerable to producer capture. The growth of new technologies of knowledge production enabled the transmission and reception of new management practices and beliefs and disrupted the established patterns of precedent and hierarchy.

The charge of being rule-bound and hierarchical, shaped by precedent and shared cultural practices, was levelled at another elite group Her Majesty's Inspectorate (HMI). Inspection of schools is a peculiarly interesting knowledgebased governing practice. In summary, in England, it was and is directly observational of sites and practices. That is, in the case of schooling, inspectors are empowered (and required) to enter the world of the school and observe what takes place within it. It is thus embodied evaluation: the inspector is a distinctive type of agent whose presence is required at the site of inspection and who embodies inspectorial knowledge, judgement and authority. Furthermore, it is a form of qualitative evaluation, involving the exercise of judgement rather than, for example, only the calculation of statistical regularity or deviation from a performance norm or target, though the relationship between performance data and judgement has tightened in recent years (Ozga 2015).

The transformation from the tradition, independence and elite status of Her Majesty's Inspectorate (HMI) to the government agency of the Office for Standards in Education (Ofsted) in England offers a good illustration of the alignment of key 
factors in the political conditions in changing knowledge production for policy. Here is Her Majesty's Chief Inspector in 1974, describing inspection:

Inspection has always been close observation exercised with an open mind by persons with appropriate experience and a framework of relevant principles (Sheila Browne, former HMCI 2003: 2)

This approach, which prioritised embodied and experiential knowledge, was set aside when Ofsted was created in 1992, because HMI, which included distinguished educationalists, were seen by the 'reforming' governments of the late 1980s/1990s as more focused on influencing government than on schools and vulnerable to producer capture. Indeed the organisational culture of Her Majesty's Inspectorate made a very strong impression on those who encountered it, including this senior member of the inspectorate, reflecting on the pre-reform culture of HMI:

....it was a certain kind of style I would characterise as militaristic and hierarchical -It was driven by the sorts of people who came into the inspectorate, certainly in the post-war period.....it was very, very powerful. I thought it was both very powerful as a means of inducting people and giving them a very good professional grounding in the business of inspection. But I was also slightly concerned that it was about adopting a rather small c conservative set of attitudes and values....

And I think there was something about the code which you almost had to just discern-it wasn't ever really taught.... when you looked at the senior ranks that was actually drawn from a much narrower educational/social stratum, a predominance of people with independent school backgrounds-quite a predominance-way out of proportion to what you'd expect normally. (former HMI)

HMI, then, exercised a form of knowledge-based power, managed through conversations and reports, which are related to their elite status, their professional community and their operational significance as the only body that linked disparate sites and practices of schooling. Their claims to authority rested on knowledge of individual schools-knowledge that was located in notes, files, reports, and lettersand circulated through their networks and publications. In the 1970s HMI produced their own research and sampling techniques for national Primary Surveys and published analytical studies of inspection reports: describing themselves as 'one of the most prolific sources of incisive, constructive pamphlets on current educational issues' (Allen 1960). Inspectors in England before 1992 expressed a strong commitment to the view that a kind of inspector-connoisseurship or artistry formed the most appropriate basis for judging schooling. The validity of their judgement was tied to 'the background, training and, most importantly, the experience of the inspector, and builds on standards that are internalised versions of collective judgments'.

However Kenneth Baker, the Secretary of State in Thatcher's government responsible for the 'modernising' Education Reform Act (1986) in England, condemned the inspectorate as 'rooted in progressive orthodoxies, in egalitarianism and in the comprehensive school system. It was devoutly anti-excellence, anti-selection, and anti-market. .... If the civil servants were guardians of this culture, then Her Majesty's Inspectors of Education were its priesthood' (Baker 1993: 168).

While HMI had been located within the government Department, enabling a degree of professional and cultural connection, Ofsted was physically separated 
from it. Ofsted was also a more dispersed organisation, with a smaller core and a large amount of outsourced employment. In relation to knowledge production, HMI had put the emphasis on observation and experience, combined with strong socialisation and a shared culture of work, but Ofsted started the move towards criteria, the use of templates for observation, and from the late 1990s to the present the increasing use of performance data to set the parameters for inspection. These forms of knowledge production placed substantial constraints on reference to and mobilisation of experiential or embodied knowledge, as we found in our recent research:

I think in England we have too much data and a lot of the inspectors don't really understand it. (...) I mean data-you can make it say anything you want it to and it's difficult to refute in an inspection, or to say something different from what the data appear to be saying. (...) you are in the bottom left hand quadrant. It's very difficult to say in a report (...) well yes you are there but in actual fact the school is much better than that-and there are reasons why, but Ofsted will say, but the data says this. (Contract inspector14)

I think that the last framework was the least professionally orientated, gave inspectors the least opportunity to use their professional judgement... because of the algorithms that existed within it. Ok so if $x$ was a grade one and y was a grade one then $z$ would have to be a grade one. (Contract inspector 11)

Attention to the prevailing political conditions highlights changes in most forms of work from the 1980s onwards-the increasingly technocratic rationalisation of work in the context of globalised production and the dominance of neo-liberal principles drives new work cultures and the relationships that accompany them, including increased employee dependency, limited and punitive contractual relations that advantage transnational employers, demand for intensified productive efforts from workers, and their heightened risk and insecurity, as well as a de-collectivisation of interests and alienation from historically embedded values. And yet work is supposed to be generating resources for the Knowledge Economy in 'Knowledge-rich continuously-learning dynamically-innovating organisations' (Casey 2013: 201). The policy orthodoxy is that for innovation and growth, 'employers need workers who actively and constantly seek out new and better ways of doing things' and not only better skill levels but 'a new, trust-based relationship between employer and employee' (EC 2010:Europe 2020).

Our research on work relations and practices in the Inspectorate in England between 2012 and 2014 found a workforce characterised by fragmentation and division, surveillance and the absence of trust. Regulation of work was accompanied by increasing data use that limited professional judgement and increased stress:

... you do go in and yes you have the data there, but when you turn up at the school, you know you can often find that it doesn't quite match. But then what you have to do though is to be able to-and this is where some inspectors find it difficult- is to make it add up if the school itself doesn't look like the picture that the data is giving you.

(INT) How to do you make it work? How do you make it all add up? If the data are telling a different story from the school?

That's where professional judgement comes in. But often you know you find that people play it safe and go with the data there is an element of that, due to the risk factor. The risk factor is common when you are less confident, less experienced....it can be difficult. (Inspector 25) 
High-risk working conditions supported and continue to support increased data dependency. In other areas, too, established expertise came under attack, as explicitly political influences became more dominant in policy. In the 1980s, political advisers appeared as a group that rapidly became a powerful source of knowledge for policy and which has increased in numbers and influence ever since. The extract below from an interview in the 1980s with Stuart Sexton, who was political adviser to six Secretaries of State from 1979 onwards, and who was very influential in introducing market principles to education, explains how he, and others who followed, worked to influence policy:
My role was in effect proposing, developing, researching what became our education policy for the 79 election and subsequently I was what's known as a special adviser to the secre- tary of state following it through and developing it further-I was probably the only one in the 70s but then others came in on it as it developed throughout the 80s.
... in addition I produce publications from the IEA, [Institute of Economic Affairs] which are widely distributed to Ministers, MPs and so called opinion formers-so publications, conferences, seminars and lots and lots of informal meetings.

Roger Scruton, the well-known conservative political philosopher, also interviewed in the 1980s, describes the influence of the Hillgate Group, which he established:

The Hillgate group is a private little club of people who share their concern about the collapse of the educational system, in particular about what was going on in state schools, and we had as our purpose to write a trenchant pamphlet at the crucial moment when the government was beginning, at last to think about these problems, in such a way if you like, that language was provided with which to formulate new policies.

These interviews, and others, stress paper production as the dominant form through which ideas were disseminated by political advisers operating in groups like the IEA and Hillgate, but they also draw attention to the importance of networks of 'opinion formers' and to the new, politicised language through which new policies could be formulated. These are not the internal, silo-based communications of bureaucracies, nor do the 'trenchant' pamphlets use the style and language of administrative memoranda. Indeed what characterises that influential writing in favour of education 'reform' in this period is the absence of evidence and the strength of the opinions expressed, as well as a determination to escape from precedent and history.

As a former Director of Education comments, considering the growth of influence of political advisers:

Well they are bloody frightening, they are. Because they are usually people with very, very little experience. Very ambitious, so this is only a step on the route. And, very opinionated. So they will have views about exactly what needs to be done, that will be influenced by the press, public opinion, and not history. From ' 74 through to '79, it was still.... the people running it [the Department of Education] were old-style civil servants, and they had excellent folk memories of how things had happened. I mean, any sense of history has gone. It's gone from the civil service as well.

(Interview TB 2013) 
This quotation, like much of the data gathered in research over a period of years with colleagues on the changing nature of knowledge production (Issakyan et al. 2008; Ozga and Lawn 2014), highlights the changing nature of the expertise involved, the growing influence of the media, and the emphasis placed on 'actionable' knowledge, involving 'real'-world translation and brokering. This is a long way from the closed world of administrative memoranda, as the quotation from a senior civil servant in the Department illustrates:

I am deeply involved in data-interpretation, management, use of, future of...I have been involved with targets, national curriculum results, what they mean and assessment ....I am a full time civil servant but importing some external expertise brings some grounding in reality to policies.

I've got people who are crack teachers, crack advisers and they're talking to children first-talking to kids first-hand about what went wrong - I think that's a professional job, not a civil servant's job.

(Interview, DfES 2007)

\subsection{Discussion}

The collaborative research referenced in this chapter provides evidence of considerable change in the material conditions of knowledge production for policy. From knowledge production based on static and centrally controlled materials stored in large files that acted as a source of guidance based on precedent, governing knowledge is now decentralised, future-oriented, networked, processual, autonomous and fluid (Issakyan et al. 2008). Its networked nature (in the sense that it is co-produced by different networks of policymakers, experts and practitioners) promotes its easy exchange and hence its operation as one of the prime engines for its marketisation within neo-liberal economies (Thrift 2005). These changes also imply the presence of new policy actors, organised in networks, translating and brokering increasingly dense digitised information. Do these policy actors constitute a new elite?

Elite theory is currently somewhat neglected, but was firmly established in the 1970s when my research began, both in the academic study of education and among those who defined themselves as policymakers (at least in England). Policy elites were understood as constituting a fairly well-defined group, connected to one another through education and experience, as well as through family background, class, gender and religion. Research on the 'assumptive worlds' of policymakers from this period describes how their social and professional identities were inextricably intertwined, while Greenaway's (1988) study of the political education of the Civil Service mandarin elite in England stressed the impact of education in shaping a commitment to the generalist all-rounder as the preferred model civil servant, characterised by integrity, detachment, and team work. The major Public Schools and ancient universities were seen as ideal training grounds for such knowledge production and were also understood to foster camaraderie, loyalty and respect for tradition (Kelsall 1954). Indeed Gail Savage found that $60 \%$ of Board 
of Education/Ministry officials in the 1940s-1960s were public school and Oxbridge products with a 'high degree of social homogeneity' (Savage 1983). Between 1900 and 1986, the Clarendon public schools were attended by three in five Permanent Secretaries and 75\% of them between 1965 and 1986 were Oxbridge men. The close ties formed among senior civil servants lasted from early school age through working life. As a Treasury official, quoted in Heclo and Wildavsky's famous study of the private governance of public money, put it:

The civil service is run by a small group of people who grew up together. (Heclo and Wildavsky 1974; 76)

The documentary analysis and interviews that Sharon Gewirtz and I carried out in the 1980s with retired officials and officers who had been active in post-war reconstruction of the system, and which are drawn on here, revealed close social networks (established at particular public schools) and through intermarriage. These were long-lasting friendships that built mutual recognition and reciprocity and were further characterised by collective sponsorship of the next generation. These policy actors were often sustained in their practical policymaking by a shared belief in the different abilities that they believed to be present in the school population, as indicated by IQ tests. Policymaking was characterised by reference to precedent, disrupted only by some anxiety about pressure for change from 'below', especially in the immediate post-war years (Lawn 1996).

The workings of post-war education policy could best be understood, on the basis of that earlier research (Gewirtz and Ozga 1990) as the management of a system through a group of highly networked individuals who ensured very considerable continuity in policy while maintaining their power and control. In classic Marxist terms, this was a positional elite, ensuring its continuing dominance through structural domination and shared-if rather implicit-ideological conviction. This elite shared a capacity to work within structures of domination (including education systems) in order to pursue their material and social interests-especially those that supported them in maintaining their position in the face of challenge 'from below'.

More recent theorisation of elites has challenged structural analysis (in this and many areas) and focused on horizontal, culturally based forms of power and control, and on distributed social relations. Indeed elite theory has become rather preoccupied with cultural elites and their shared educational experiences (see, e.g. van Zanten et al. 2015). There is considerable potential, however, in extending the range of engagement with elites, including through the lens of expertise and the production of policy knowledge, in order to highlight change in elite strategies of knowledge production and to illustrate how they intersect with governing forms. One effect of the current controversies and the hostility expressed towards elites in populist discourse has been to revive theoretical and empirical work in this area, as political scientists and sociologists of policy seek to understand the intersection between the possession of economic, cultural and political capital and the growth of consultancy, technology and new governing networks (Ball and Junemann 2012; Normand 2016). In the UK, John Scott's (2008) work has consistently drawn attention to elite capacity to exercise both structural power through its capacity to store and hold 
power, while also observing and recognising the fluidity of structures of domination and their capacity to function as dynamic institutional formations, subject to change and development. In Reed's words, such an approach to elites combines the 'storage and holding of power' with the 'exercise and mobilization of power' (Reed 2012: 210) including through the knowledge-policy relationship.

In this chapter, I have attempted to explore the growth of new elites (experts) in conjunction with the growth of data and its dominance in policymaking. Research conducted since 2006 traces the rise of data, the increasing dependency of policymakers on data to provide 'actionable knowledge' and the parallel growth of consultancy. In our research on the rise of data in Europe, we identified the growth of technical expertise and the increased power of technocrats in framing policy issues and their solutions (Ozga and Grek 2012). More recent research identifies a European technocracy that is developing 'epistemic' governance, using its skills and capacities to consolidate and extend its authority and power (Normand 2016: 129).

The contrast with the 'data-free' period of the 1970s is evident if we focus on what Freeman calls 'the real things, that is, the objects, tools, instruments and artefacts' with which people engage in the practice of policy. These artefacts, as I have tried to show, are not inert, but structure practices (Fenwick and Edwards 2014). The artefact or object — an administrative memorandum, an algorithm—expresses and shapes knowledge, communicates knowledge and codifies it. It carries implicit and explicit messages, in the 1970s, about the importance of experience, and precedent, in contemporary contexts, about the need for speed and forward-thinking. The artefacts discussed here do indeed suggest that the elites have changed and that expertise is located in a different place and takes a different form from that prevailing in the past in England. But such a large question —on the nature of elites - cannot be 'answered' in a short and selective account of research such as this. What I do suggest, however, is that widening our approaches to policy as a topic, to include what Thrift (2005) calls 'mundane materials' and their active role in producing and constituting knowledge for policy, will add a missing dimension to our understanding of the role of experts and elites in policymaking.

\section{References}

Allen, G. C. (1960). H.M. Inspectors of schools: A personal impression. International Review of Education, 6(2), 235-239.

Anderson, C. (2008, June 23). The end of theory: The data deluge makes the scientific method obsolete. Wired. Retrieved July 3, 2015, from www.wired.com/2008/06/pb-theory/.

Baker, K. (1993). The turbulent years. London: Faber and Faber.

Ball, S., \& Junemann, C. (2012). Networks, new governance and education. Bristol: Polity.

Bevir, M. (2013). A theory of governance. GAIA Books, University of California. Retrieved from http://escholarship.org/uc/item/2qs2w3rb. 
Casey, C. (2013). Workers, citizens and lifelong learning: The search for sociocultural Innovation. In F. Garibaldo, M. Baglioni, C. Casey, \& V. Telljohan (Eds.), Workers, citizens, governance. Frankfurt am Main: Peter Lang.

Clarke, J., \& Newman, J. (2017). 'People in this country have had enough of experts': Brexit and the paradoxes of populism. Critical Policy Studies, 11(1), 101-116. https://doi.org/10.1080/1 9460171.2017.1282376.

Clarke, J., Bainton, D., Lendvai, N., \& Stubbs, P. (2015). Making policy move: Towards a politics of translation and assemblage. Bristol: The Policy Press.

Connell, R. (2007). Southern theory: The global dynamics of knowledge in social science. Cambridge: Polity Press.

Cutler, T., \& Waine, B. (1998). Managing the welfare state. Text and sourcebook. Oxford: Berg.

Dale, R. (2000). Globalisation and education. Education Theory, 50(4), 427-449.

Demszky, A., \& Nassehi, A. (2014). The role of knowledge in scientific policy advice. In T. Fenwick, E. Mangez, \& J. Ozga (Eds.), World Yearbook of Education: Governing knowledge: comparison, knowledge-based technologies and expertise in the regulation of education (pp. 113-127). London: Routledge.

EU (European Commission) Europe 2020: A European strategy for smart, sustainable and inclusive growth Brussels, 3.3.2010 com(2010) 2020.

Fazekas, M., \& Burns, T. (2012). Exploring the complex interaction between governance and knowledge in education. OECD education working papers, no. 67, OECD Publishing. https:// doi.org/10.1787/5k9flcx21340-en.

Fenwick, T., \& Edwards, R. (2014). Network alliances: Precarious governance through data, standards and code. In T. Fenwick, E. Mangez, \& J. Ozga (Eds.), Governing knowledge: Comparison, knowledge-based technologies and expertise in the regulation of education (world yearbook of education 2014) (pp. 101-113). London: Routledge.

Fox, K., \& O'Connor, J. (2015). Five ways work will change in the future. Retrieved from https://www.theguardian.com/society/2015/nov/29/five-ways-work-will-change-future-ofworkplace-ai-cloud-retirement-remote.

Freeman, R., \& Sturdy, S. (2014). Knowledge in policy: Embodied, inscribed, enacted. London: Policy Press.

Gewirtz, S., \& Ozga, J. (1990). Partnership, pluralism and education policy: A reassessment. Journal of Education Policy, 5(1), 37-48.

Gewirtz, S., \& Ozga, J. (1994). Interviewing the education policy elite. In G. Walford (Ed.), Researching the powerful in education. London: UCL Press.

Greenaway. (1988). The political education of the civil service mandarin elite. In R. Fieldhouse (Ed.), The political education of servants of the state. Manchester: Manchester University Press.

Grek, S. (2015). Seeing from the top of the tower: PISA and the new governing panoramas in Europe. Compare - A Journal of Comparative and International Education, Forum, 45(3), 479-481.

Grek, S., \& Lindgren, J. (Eds.). (2015). Governing by inspection: School inspection in Scotland, Sweden and England. Oxford: Routledge.

Grek, S., \& Ozga, J. (2010). Re-inventing public education: The new role of knowledge in education policy-making. Public Policy and Administration, 25(3), 271-288.

Grundmann, R., \& Stehr, N. (2012). The power of scientific knowledge. Cambridge: Cambridge University Press.

Hartong, S. (2015). Global policy convergence through "distributed governance"? The emergence of "national" education standards in the US and Germany. Journal of International and Comparative Social Policy, 31(1), 10-33.

Heclo, H., \& Wildavsky, A. (1974). The private government of public money. London: Macmillan.

Higgins, V., \& Larner, W. (Eds.). (2012). Calculating the social: Standards and the reconfiguration of governing. London: Palgrave Macmillan. 
House of Commons. (1975-1976). Tenth report of the Expenditure Committee: Policy-making in the Department of Education and Science (pp. 6-7). London: HMSO.

Issakyan, I., Lawn, M., Ozga, J., \& Shaik, F. (2008). The social and cognitive mapping of policy: The education sector in Scotland. KnowandPol Orientation 1, FinalReport. Retrieved from http://www.knowandpol.eu/fileadmin/KaP/content/Scientific_reports/Orientation1/O1_Final_ Report_Scotland_educ.pdf.

Jessop, B., Fairclough, N., \& Wodak, R. (2008). The knowledge-based economy and higher education in Europe. London: Routledge.

Kelsall, R. K. (1954). The social background of the higher civil service. The Political Quarterly, 25(4), 382-389.

Lawn, M. (1996). Modern times? Work, professionalism and citizenship in teaching. Lewes: Falmer Press.

Lawn, M., \& Grek, S. (2012). Europeanizing education: governing an emerging policy space. Oxford: Symposium.

Lawn, M., \& Lingard, B. (2002). Constructing a European policy space in educational governance: The role of transnational policy actors. European Educational Research Journal, 1(2), 290-307.

Normand, R. (2016). The changing epistemic governance of European education. Rotterdam: Springer.

Ozga, J. (2015). Working knowledge: Data, expertise and inspection in the governing of education. In H.-G. Kotthoff \& E. Klerides (Eds.), Governing educational spaces: Knowledge, teaching, and learning in transition (pp. 15-35). Rotterdam: Sense Publishers.

Ozga, J. (2016). Trust in numbers? Digital education governance and the inspection process. European Educational Research Journal, 15(1), 69-82.

Ozga, J., \& Grek, S. (2012). Governing through learning: School self-evaluation as a knowledgebased regulatory tool. Recherches sociologiques et anthropologiques, 2012/2, 83-103.

Ozga, J., \& Lawn, M. (2014). Frameworks of regulation: Evidence, knowledge and judgement in inspection introduction to special issue of Sisyphus. Journal of Education, 2(1), 7-16.

Ozga, J., Dahler-Larsen, P., Segerholm, C., \& Simola, H. (Eds.). (2011). Fabricating quality in education: Data and governance in Europe. London: Routledge.

Ozga, J., Baxter, J., Clarke, J., Grek, S., \& Lawn, M. (2012). The politics of educational change: Governance and school inspection in England and Scotland. Swiss Journal of Sociology, 39(2), 205-224.

Piattoeva, N. (2014). Elastic numbers: National examinations data as a technology of government. Journal of Education Policy, 30(3), 316-334.

Reed, M. (2012). Masters of the universe: Power and elites in organization studies. Organization Studies, 33(2), 203-221.

Rose, N., \& Miller, P. (1992). Political power beyond the state: Problematics of government. The British Journal of Sociology, 43(2), 173-205.

Savage, G. (1983). Social class and social policy: The Civil Service and Secondary Education in England during the Interwar Period. Journal of Contemporary History, 18(2), 261-280.

Scott, J. (2008). Modes of power and the reconceptualisation of elites. In M. Savage \& K. Williams (Eds.), Remembering elites. Oxford: Blackwell Publishing.

Shiroma, E. O. (2014). Expert consultants and knowledge production. In T. Fenwick, E. Mangez, \& J. Ozga (Eds.), Governing knowledge: Comparison, knowledge-based technologies and expertise in the regulation of education (World Yearbook of Education 2014) (pp. 101-113). London: Routledge.

Stone, D. (2013). Knowledge actors and transnational governance: The private-public policy Nexus in the global agora. Hampshire: Palgrave Macmillan.

Thrift, N. (2005). Knowing Capitalism. London: Sage.

Williamson, B. (2016). Digital methodologies of education governance: Pearson plc and the remediation of methods. European Educational Research Journal, 15(1), 34-54. 
Zammuto, R., Griffith, T., Majchrzak, M., Dougherty, D., \& Faraj, S. (2007). Information technology and the changing fabric of organization. Organisation Science, 18(5), 749-762.

van Zanten, A., Ball, S., \& Darchy-Koechlin, B. (Eds.). (2015). Elites, privilege and excellence. The National and Global Redefinition of Educational Advantage, World Yearbook of Education. London: Routledge.

Jennifer T. Ozga is Professor Emeritus in the Department of Education, the University of Oxford, where she was Professor of Sociology from 2010 to 2015, and she is also an Honorary Professorial Visiting Fellow in the School of Social and Political Sciences, the University of Edinburgh. Before Oxford, she was Director of the Centre for Educational Sociology (CES), University of Edinburgh. She is a Fellow of the British Academy and of the Academy of Social Sciences and has been a visiting scholar at Helsinki University, Finland. Jenny's current research, funded by a Leverhulme Emeritus Fellowship, is on Governing Education: Knowledge and Policy in England and Scotland since 1986. It investigates the changing relationship between knowledge and policy in governing education in that period, with a focus on the changing forms of knowledge available to policy actors, and the effects of these changing knowledges (e.g. the growth of statistics, digital media and data) on their work processes and relations.

Open Access This chapter is licensed under the terms of the Creative Commons Attribution 4.0 International License (http://creativecommons.org/licenses/by/4.0/), which permits use, sharing, adaptation, distribution and reproduction in any medium or format, as long as you give appropriate credit to the original author(s) and the source, provide a link to the Creative Commons licence and indicate if changes were made.

The images or other third party material in this chapter are included in the chapter's Creative Commons licence, unless indicated otherwise in a credit line to the material. If material is not included in the chapter's Creative Commons licence and your intended use is not permitted by statutory regulation or exceeds the permitted use, you will need to obtain permission directly from the copyright holder.

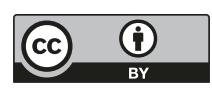

